\title{
Connections of Trapezoidal Sheets under Fire
}

\author{
P. Kallerová, F. Wald, Z. Sokol
}

This paper describes two different experiments on connections of trapezoidal sheets under elevated temperatures. The first experiments were tensile tests carried out on four sets of tests with screwed connections under ambient and elevated temperatures. One diameter of self-drilling screws and three different thicknesses of trapezoidal sheets were used. The applied screws were without washers, or with sealed or steel washers. The second experiment was performed in a laboratory furnace to check the catenary action of a thin-walled trapezoidal sheet. The basic theory tested in this experiment was that in the first phase of the fire the sheet behaves as a simply supported beam, while in the second phase the load bearing is transferred by a tension membrane. These experiments will be used to develop a design model of connections at high temperatures. High fire resistance of the trapezoidal sheet, dependent on suitable design of the screwed connection to the bearing structure, was confirmed. The experiment with the simple beam also confirmed catenary action.

Keywords: Screwed connection, self-drilling screw, trapezoidal sheet, elevated temperature, catenary action.

\section{Introduction}

The behaviour of a steel structure under a fire situation differs from its behaviour under ambient temperature. The mechanical properties and the thermal expansion change with increasing temperature. Especially the yield stress and the modulus of elasticity have a significant influence on the bearing capacity of steel members. This is significant especially for thin-walled elements. A corrugated sheet is able to transfer the bending moments in the early phase of the fire. The thermal expansion of steel extends the sheet and results in increased deflection. At this stage, the bolted connection is loaded by forces induced by thermal expansion. At higher temperatures, the bending moment resistance is reduced and a major part of the load is transferred by the tension membrane. At this moment, the resistance and stiffness of the bolted connection has a significant influence on the sheet behaviour. The connections transfer the membrane force to the supports. The performance of the connection is also important in the cooling phase of the fire.

The resistance of the connection is expressively influenced by the change in the mechanical properties of the corrugated sheet. The increase in the temperature leads to a decrease in the yield stress and the modulus of elasticity of thin-walled cold formed steel members. The decrease in these mechanical properties leads to a reduction in the load bearing capacity of the structure. However, the ultimate strength is slightly increased for higher temperatures. The maximum strength is reached at $250{ }^{\circ} \mathrm{C}$, and the original value is obtained at about $350^{\circ} \mathrm{C}$. An additional increase in temperature leads to a decrease in bearing capacity. For temperatures higher than $400{ }^{\circ} \mathrm{C}$, the yield stress on the force-deformation diagram is not visible. Buckling of thin walled elements is influenced by the reduced modulus of elasticity value.

\section{Description of experiment and tested specimens}

\subsection{Experiments with screwed connections}

Two sets of tests with screwed connections under ambient and elevated temperatures were carried out in the laboratory of the Faculty of Civil Engineering of the Czech Technical University in Prague. In these experiments, the mechanical properties of screwed connections at steady state conditions were determined. Steady state tests (SST) are faster and simpler than transient state tests. SSTs can be used for predicting behaviour in fire situations, when the temperature changes in time [1]. The experiments focused on the stiffness, resistance, deformation capacity and collapse mode of the connections during fire.

Four sets of experiments have been performed. In 2005, two sets of tests were carried out [2]. In set A, E-VS BOHR $5-5.5 \times 38$ screws and a sealed washer $\varnothing 19 \mathrm{~mm}$ were used. In set $\mathrm{B}$, the same screws were used, but the sealed washer was replaced by a steel washer $29 \mathrm{~mm}$ in diameter. The thickness of the trapezoidal sheet for sets A and B was $0.75 \mathrm{~mm}$. The next two sets of experiments were carried out in 2007 [3]. The screwed connections in the test were made with the use of self-drilling carbon steel screws marked SD8-H15-5.5×25 (set $\mathrm{C}$ and set D). The test specimens were cut out from a trapezoidal sheet with nominal thickness $0.75 \mathrm{~mm}$. In test set $\mathrm{C}$, trapezoidal sheets with measured thickness $0.75 \mathrm{~mm}$, width $75 \mathrm{~mm}$ and length $500 \mathrm{~mm}$ were tested. The specimens for test set $\mathrm{D}$ were from measured sheet $0.80 \mathrm{~mm}$ in thickness, $50 \mathrm{~mm}$ in width and $350 \mathrm{~mm}$ in length. The values of the material properties of the trapezoidal sheet were obtained by material experiments. For measured sheet thickness $0.75 \mathrm{~mm}$, the yield stress was $338 \mathrm{MPa}$, and the ultimate strength was $428 \mathrm{MPa}$. For measured sheet thickness $0.80 \mathrm{~mm}$, these values were $327 \mathrm{MPa}$ for the yield stress and $426 \mathrm{MPa}$ for the ultimate strength.

In each set of tests, experiments were performed with two specimens for ambient temperature $20{ }^{\circ} \mathrm{C}$ and for constant elevated temperatures $200{ }^{\circ} \mathrm{C}, 400{ }^{\circ} \mathrm{C}, 500{ }^{\circ} \mathrm{C}, 600{ }^{\circ} \mathrm{C}$ and $700^{\circ} \mathrm{C}$. Steel sheets $10 \mathrm{~mm}$ in thickness simulated the bearing roof structure and they were anchored into the grips of the testing machine, see Fig. 1. Due to these thicker sheets, the force from testing machine to the specimens was transferred. The tested screwed joints were placed in the middle in the electric furnace. The specimens tested in 2006 were heated in an electric furnace with internal diameter $150 \mathrm{~mm}$ and height $300 \mathrm{~mm}$. The temperatures of the connection were measured by a thermocouple attached to the steel sheet close 

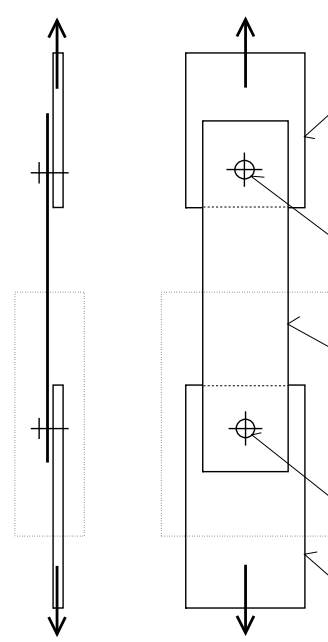

Steel plate $t=10 \mathrm{~mm}$

fixed to testing machine

Bolted connection, standard bolt M12

Test specimen $t=0.75 \mathrm{~mm}$

The tested connection in the furnace

Screw SD8 - H15 - $5.5 \times 25$

Steel plate $t=10 \mathrm{~mm}$

fixed to testing machine

Fig. 1: The test set up

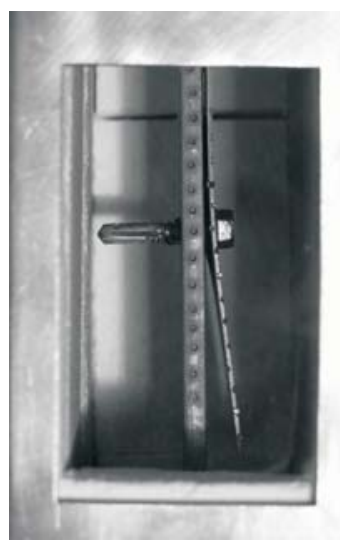

$1 \min 10 \mathrm{~s}$

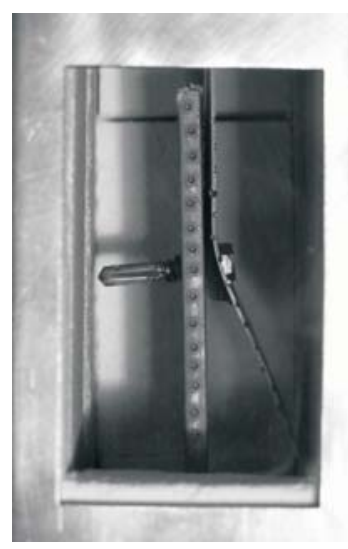

$2 \min 15 \mathrm{~s}$

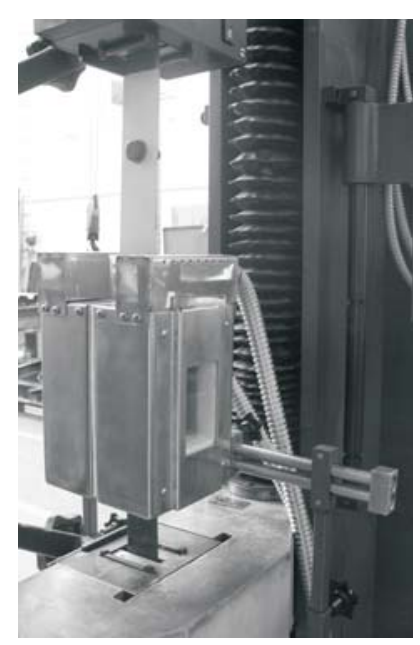

Fig. 2: Electric furnace for the tests in 2007

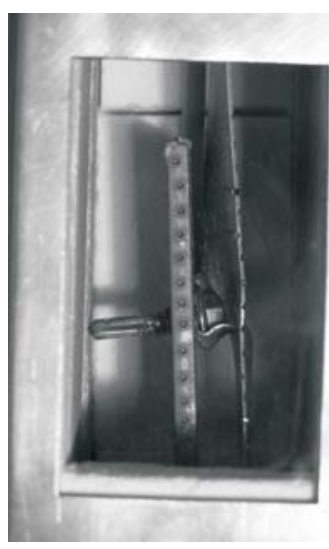

$4 \min 15 \mathrm{~s}$

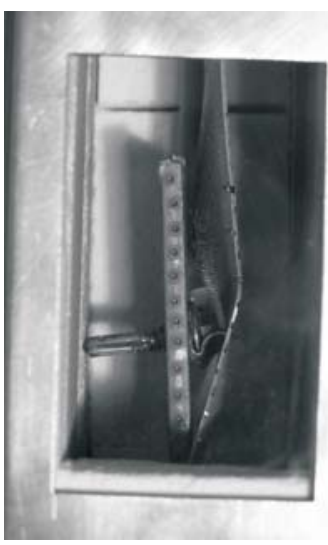

$4 \min 45 \mathrm{~s}$
Fig. 3: The deformation of the connection

to the bolt. The experiments from 2007 were carried out in a smaller furnace with one opening and internal dimensions $50 \times 130 \times 125 \mathrm{~mm}$, see Fig. 2 . The thermocouple for measuring the temperature of the connection was located in a hole drilled in the screw head. The air temperatures in the furnaces and the temperatures of the tested connections were measured by one thermocouple.

The electric furnace had one opening, which was filled with glass with high temperature protection. During the fire tests, the behaviour and the deformation of the tested connections could be observed. In the course of the experiments, photo documentation was provided at 5 -second intervals. Fig. 3 shows four photographs taken during one of the tests. The edges of the specimens were marked at $5 \mathrm{~mm}$ spacings for displacement measurement. The constant rate of movement was established.

\subsection{Experiment with a trapezoidal sheet and its catenary action}

In 2007, the PAVUS laboratory in Veselí nad Lužnicí provided a fire experiment for checking the catenary effect of a thin-walled trapezoidal sheet. The specimen for the fire experiment was taken from a trapezoidal sheet with sheet thickness $0.75 \mathrm{~mm}$, and the waves were $55 \mathrm{~mm}$ in height.
This sheet was placed above a furnace with diesel burners. The specimen was fastened by self-drilling SD8-H15-5.5×25 screws to the bearing steel frame, which was made from HEB200 profiles. The inner dimension of this frame was $800 \times 3000 \mathrm{~mm}$. In each lower wave of trapezoidal sheet two

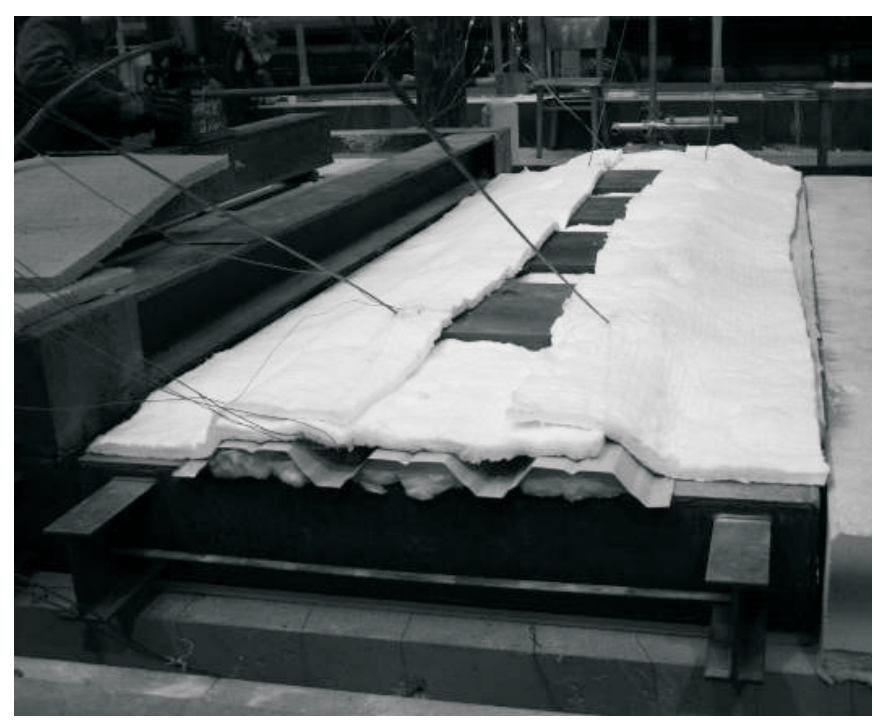

Fig. 4: The tested specimen before the fire experiment 
self-drilling screws were used. Thermal insulation protected the frame against the effect of high temperatures.

Four rectangular iron plates $30 \mathrm{~mm}$ in thickness, with dimensions $450 \times 580 \mathrm{~mm}$ and weight $60 \mathrm{~kg}$ each were used as the mechanical load. The total load on the tested specimen was $240 \mathrm{~kg}$, which corresponds to $1 \mathrm{kN} / \mathrm{m}^{2}$. The iron plates were uniformly distributed on the trapezoidal sheet. The distance between the load and the edge of the specimen was 300 $\mathrm{mm}$, and the distance from each other was $200 \mathrm{~mm}$. Fig. 4 shows a view of the tested specimen before the fire experiment. The trapezoidal sheet, the mechanical load, the bearing frame and the thermal insulation of the whole specimen can be seen.

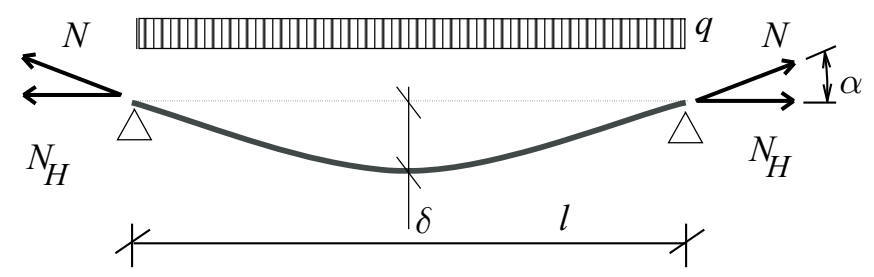

Fig. 5: The catenary action on a simply supported beam

The thermocouples and a vertical deflectometer in the middle of the span of the simple beam were located directly on the sheet. The thermocouples were placed in the midspan and at the quarter distance of the span of the trapezoidal sheet, three on the screws and three near the screws on the sheet. Two thermocouples were used for measuring the gas temperature in the furnace; they were placed at a distance of $350 \mathrm{~mm}$ from the upper surface of the upper wave of the sheet.

\section{Results of experiments}

\subsection{Experiments with screwed connections}

The resistance of the connection with a sealed washer (set A) was limited by the bearing resistance of the thin sheet. The sealant washer has no influence on the behaviour, because the sealant burns at higher temperatures. The stiffness of the connection with steel washers (set B) was much higher and the resistance was almost twice as high as for the previous set. The thin sheet was deformed and accumulated in front of the washer. This was accompanied by the formation of two shear zones on both sides of the washer, see Fig. 6 . This failure mode is characterized by deformation capacity larger than $30 \mathrm{~mm}$. However, at temperatures higher than $500{ }^{\circ} \mathrm{C}$ shear failure of the bolt was observed, see Fig. 7 .

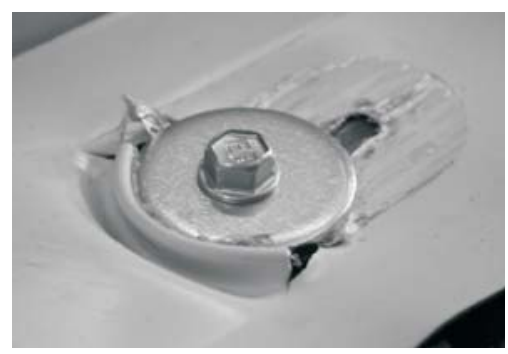

Fig. 6: The collapse mode of the connection from set $\mathrm{B}$, temperature $200^{\circ} \mathrm{C}$

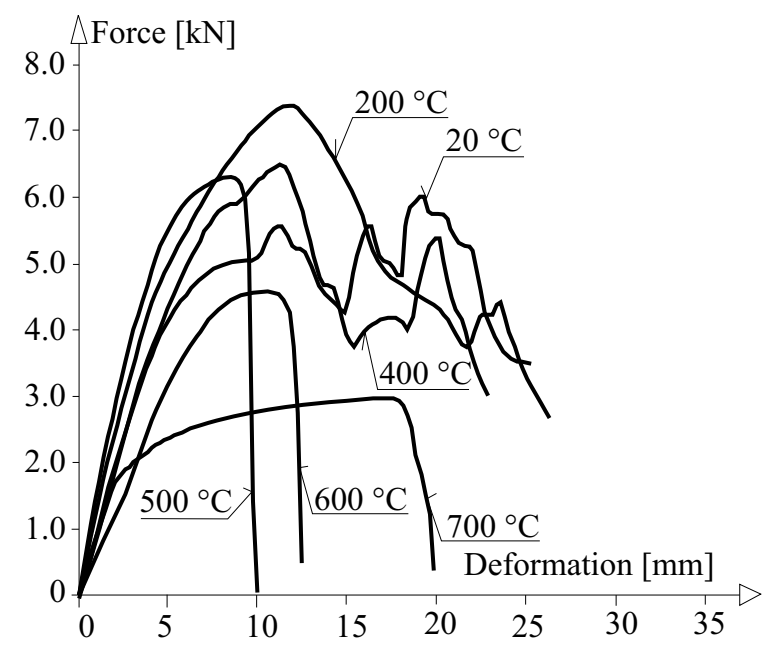

Fig. 7: Force-displacement diagrams of the screwed connections from set B

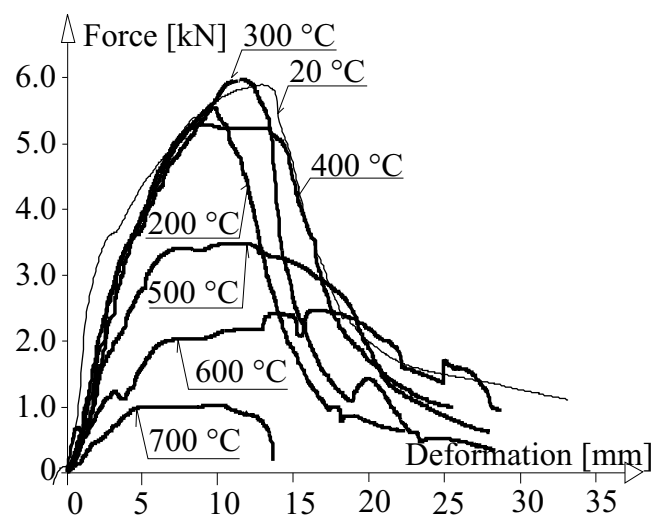

Fig. 8: Force-displacement diagrams of the screwed connection from set D

Fig. 8 is a force-deformation diagram of the connections from set $\mathrm{D}$, and the collapse mode for the connection from set $\mathrm{C}$ is shown in Fig. 9. For all specimens with a measured sheet thickness of $0.75 \mathrm{~mm}$, failure in bearing was reached when the trapezoidal sheet tore. Two modes of failure were observed for sheet thickness $0.80 \mathrm{~mm}$. For temperatures from $20^{\circ} \mathrm{C}$ to $600{ }^{\circ} \mathrm{C}$ the sheet failed in bearing, whereas for a temperature of $700{ }^{\circ} \mathrm{C}$ the mode of failure was shear failure of the screw.

In the initial phase of loading, elastic behaviour can be observed. Then the force increased until the maximum bearing capacity was achieved and the tearing of the sheet occurred. In the next phase of the force-deformation diagram, a de-

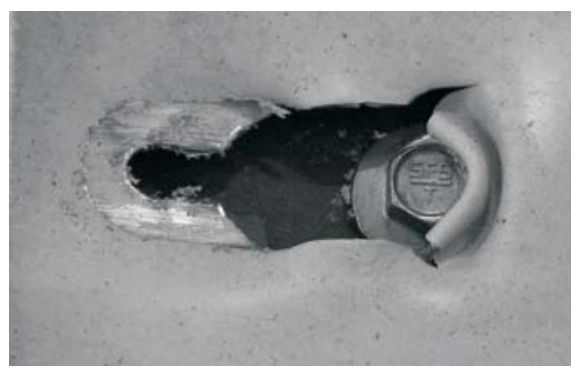

Fig. 9: Collapse mode of the connection from set C, temperature $200{ }^{\circ} \mathrm{C}$ 
crease in force can be observed. The increase and subsequent decrease in force due to the accumulation of deformed sheet in front of the screw can be seen in the diagram. The deformation capacities of the connections were high. Due to the dimension limits of the electrical furnace, all the experiments were terminated before their ultimate failure, but after exhaustion of the residual bearing capacity.

The results of these experiments show how the temperature increase leads to a decrease in the bearing capacity of the connections. For a temperature of $550{ }^{\circ} \mathrm{C}$, the bearing capacity of the connection is reduced to approximately one half of the bearing capacity under ambient temperature, and for a temperature of $700{ }^{\circ} \mathrm{C}$ the bearing capacity is less than $20 \%$ of the bearing capacity under ambient temperature. A reduction of $45 \%$ for temperature $500{ }^{\circ} \mathrm{C}$ and of $90 \%$ for $700{ }^{\circ} \mathrm{C}$ is used for calculations of connections with bolts and nuts. The experiments confirm a greater reduction in the resistance of the self-drilling screws in bearing in the initial phase of heating (up to temperature $550{ }^{\circ} \mathrm{C}$ ), and a smaller reduction for higher temperatures. These two factors lead to unfavourable brittle failure of the connection in shear [4].
Temperatures lower than $500{ }^{\circ} \mathrm{C}$ have no significant influence on the initial stiffness of the connection. The deformation capacity for higher temperatures is reduced by failure of the screw in shear. This mode of failure occurred only for the screwed connection with sheet thickness $0.80 \mathrm{~mm}$ and temperature $700{ }^{\circ} \mathrm{C}$.

\subsection{Experiment on the trapezoidal sheet and its catenary action}

The fire load was modelled by a multilinear fire curve simulating the fire load used for the fire tests in Cardington. The usage of similar fire curves is helpful for subsequent comparison of the results from different fire experiments. The maximum measured gas temperature in the furnace was $1096{ }^{\circ} \mathrm{C}$. This value was reached in the 55 th minute, and the total length of the fire experiment was 2 hours. The temperature of the trapezoidal sheet above the support was $447^{\circ} \mathrm{C}$, and this temperature is about $58 \%$ lower than the temperature of the trapezoidal sheet in the midspan $\left(1084{ }^{\circ} \mathrm{C}\right)$, see Fig. 10. In the case of an unprotected load-bearing structure the temperature would be higher.

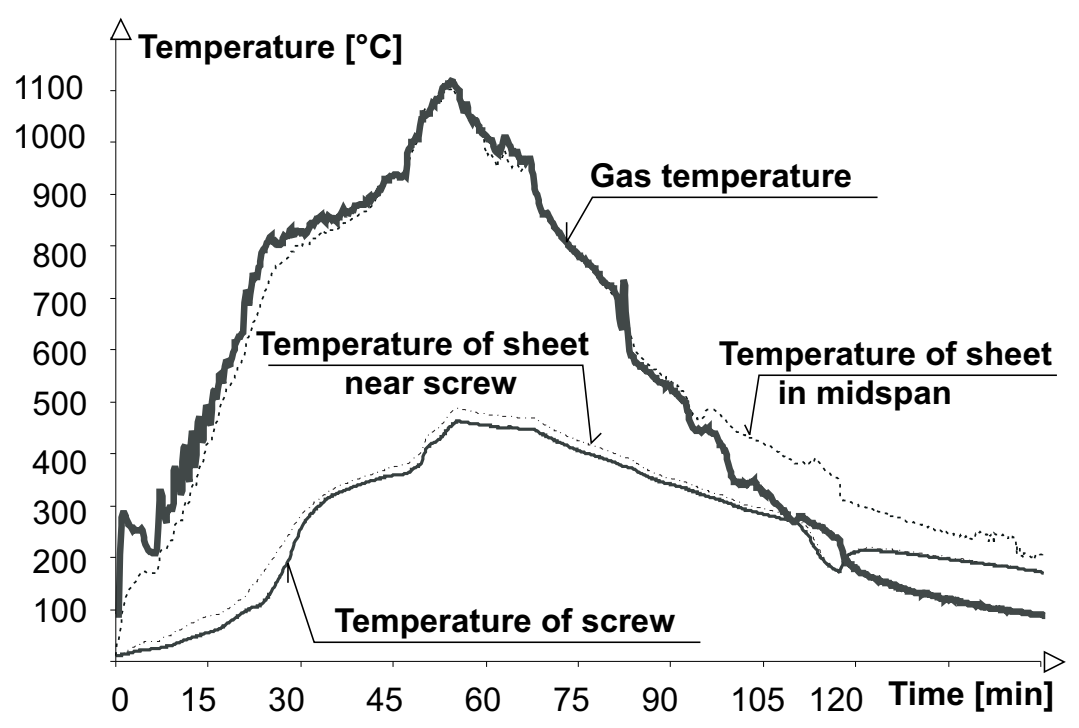

Fig. 10: Measured temperature on the specimen

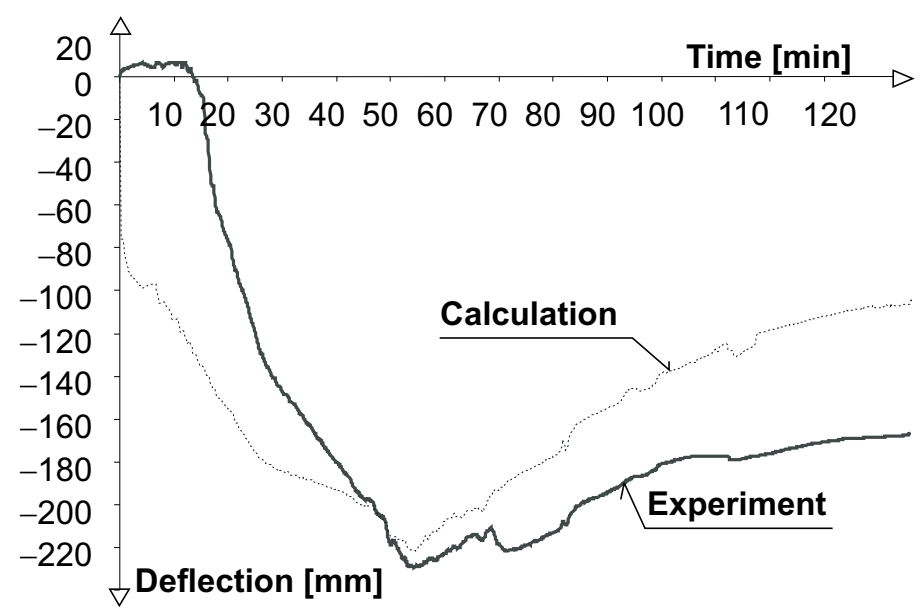

Fig. 11: Vertical deformations in the midspan of the trapezoidal sheet 
The behaviour of the trapezoidal sheet during the fire experiment was similar to the behaviour of a simple beam on which the elongation is restrained. At the beginning of the fire test, the temperatures are low and the trapezoidal sheet is not deflected by the influence of the temperature. The sheet elongates in its plane, and the screws in the supports are loaded in shear. As the temperature increases, an extension occurs as a result of the thermal expansion of the material, and the yield stress and the modulus of elasticity decrease. As a result of these effects, the deflection is increased. The increase in the deflection and the decrease in bending stiffness lead to a change in the tensile forces in the supports, and the sheet starts to behave like a tensile membrane. This effect is known as catenary action. Fig. 5 shows a scheme of the catenary action on a simply supported beam.

The collapse of the structure depends on the bearing capacity of the connections and on the ability of the load bearing structure to carry the tensile forces. Fig. 11 compares the deflection as a function of time for values calculated by equations and for values obtained during the experiment. The comparison of the maximum deflections and the times where the deflection are obtained are in a good agreement. The maximum measured deflection of the trapezoidal sheet was $229 \mathrm{~mm}$, and the calculated vertical deformation was $222 \mathrm{~mm}$.

\section{Summary}

The resistance of the connection in relation to temperature is shown in Fig. 12. Resistance is reduced at higher temperatures; the reduction is small at temperatures up to $400{ }^{\circ} \mathrm{C}$ but significant at temperatures higher than $500{ }^{\circ} \mathrm{C}$. The diameter of the washer or of the screw head has a significant influence on the resistance. The resistance of the screwed connection from set A is approximately $40 \%$ lower than the resistance of the screwed connection from set $\mathrm{D}$. When the connection from set $\mathrm{B}$ is used, the resistance is similar to the connection from set C. Shear failure of the screw may lead to low deformation capacity at temperatures higher than $500{ }^{\circ} \mathrm{C}$. These experiments will be used for developing a design model of connections at high temperatures.

The experiment with a trapezoidal sheet supported like a simple beam confirmed the catenary action. High fire resistance of the trapezoidal sheet, depending on suitable design of the screwed connection to the bearing structure, was also confirmed.

\section{Acknowledgment}

This outcome has been achieved with financial support from the Ministry of Education, Youth and Sports, under project no. $1 \mathrm{M} 0579$.

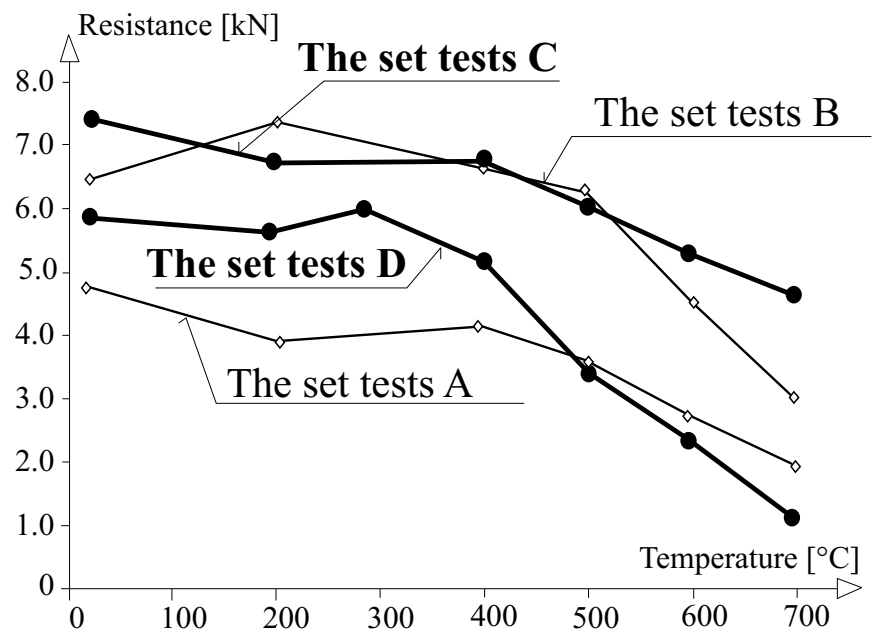

Fig. 12: Resistance of the connections

\section{References}

[1] Outinen, J.: Mechanical Properties of Structural Steels at High Temperatures and after Cooling Down. Espoo, 2007.

[2] Sokol, Z.: Design of Corrugated Sheets Exposed to Fire, Progress in Steel, Composite and Aluminium Structures, 2006.

[3] Kallerová, P.: Experiments with Bolted Connections - Experiments at Normal and Elevated Temperatures. Research report CTU in Prague, 2007.

[4] Wald, F. et al.: Calculation of the Fire Resistance of Structures. CTU in Prague, 2005.

Petra Kallerová

e-mail: petra.kallerova@fsv.cvut.cz

František Wald

Zdeněk Sokol

Department of Steel and Timber Structures

Czech Technical University in Prague

Faculty of Civil Engineering

Thákurova 7

16629 Prague 6, Czech Republic 